\title{
THE EFFECT OF PAREDRINE ON THE VENOUS SYSTEM. ${ }^{1}$
}

\author{
By ARNOLD IGLAUER AND MARK D. ALTSCHULE
}

(From the Medical Research Laboratories and Medical Service, Beth Israel Hospital, and the Department of Medicine, Harvard Medical School, Boston)

(Received for publication February 5, 1940)

In the preceding paper (1), the effect of the number of authors have associated the pressor administration of paredrine on the cardiac output action of paredrine and related drugs with con-

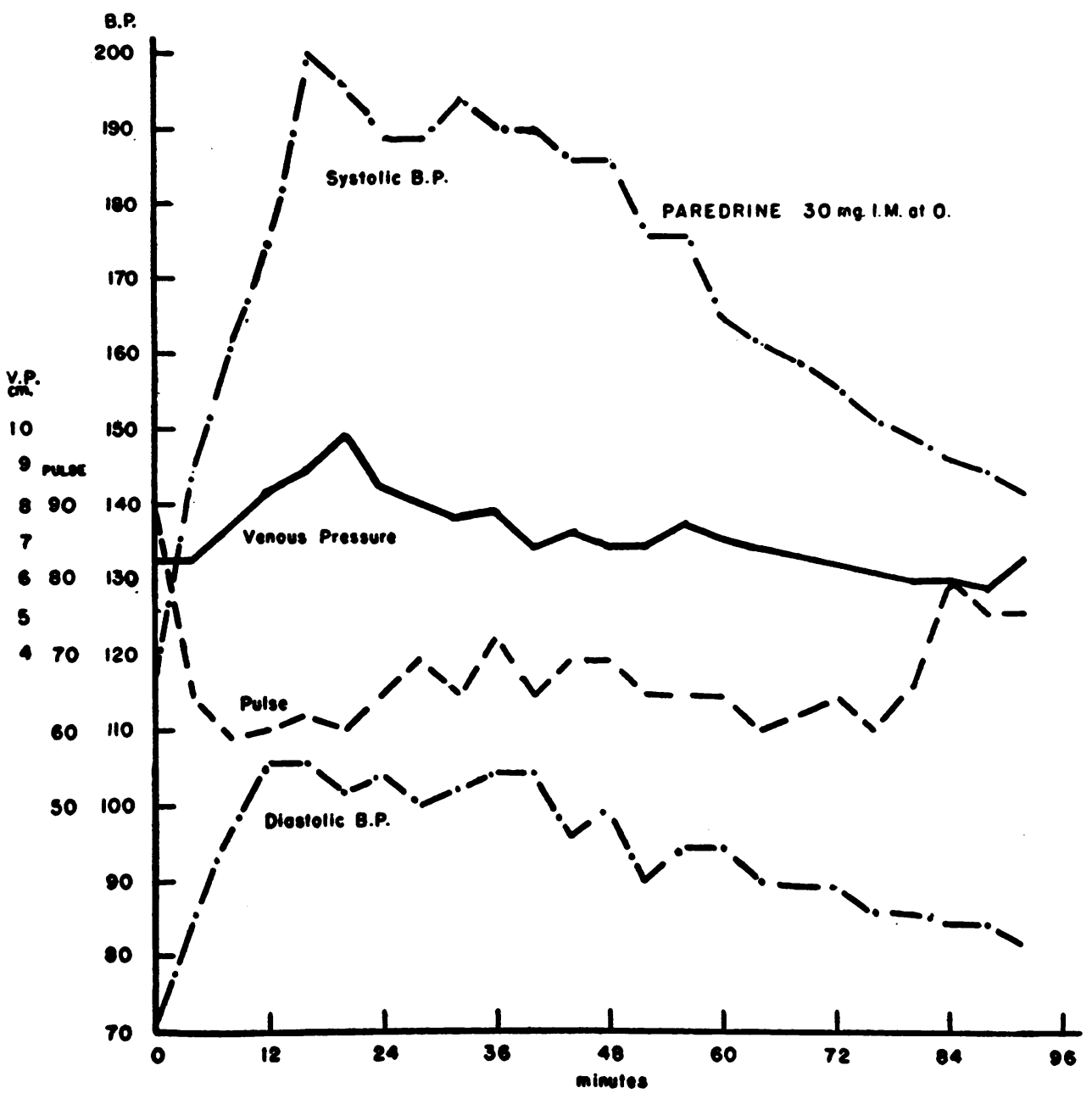

Fig. 1. Increase of Antecubital Venous Pressure after the Administration of Paredrine INTRAMUSCULARLY

and blood pressure of normal man was described. Marked elevation of systolic and diastolic blood pressure occurred, but no change in cardiac output other than occasional slight initial decrease associated with vagal inhibition was noted. A striction of the veins and "venous depots" $(2,3$, $4,5,6)$. Since data bearing on this point are inconclusive, it was considered desirable to investigate the effect of paredrine on the veins.

\section{METHODS}

Studies were made of the effect of paredrine on the venous pressure in man when given orally, intramuscu- 
larly, and intravenously. In two of these experiments, the administration of paredrine was preceded by the injection of $2.5 \mathrm{mgm}$. of atropine. In two experiments adrenalin was given intravenously in order to compare its action with that of paredrine. The subjects used in these experiments ranged in age from 17 to 50 ; none showed clinical evidences of abnormal cardiovascular function. All studies were made with the subject in the recumbent position at least 2 hours after the last meal; the drug was not given until pulse, blood pressure, and the drug was given by mouth. Blood pressure was measured by a second observer in the opposite arm at 2minute intervals by the auscultatory method, using a standard cuff. Radial pulse rate was counted every 2 minutes.

The above-described studies established the degree of change in the venous system after the administration of paredrine and to some extent also defined the mechanism of this change. In order to evaluate the importance of changes in the venous system on the genesis of the

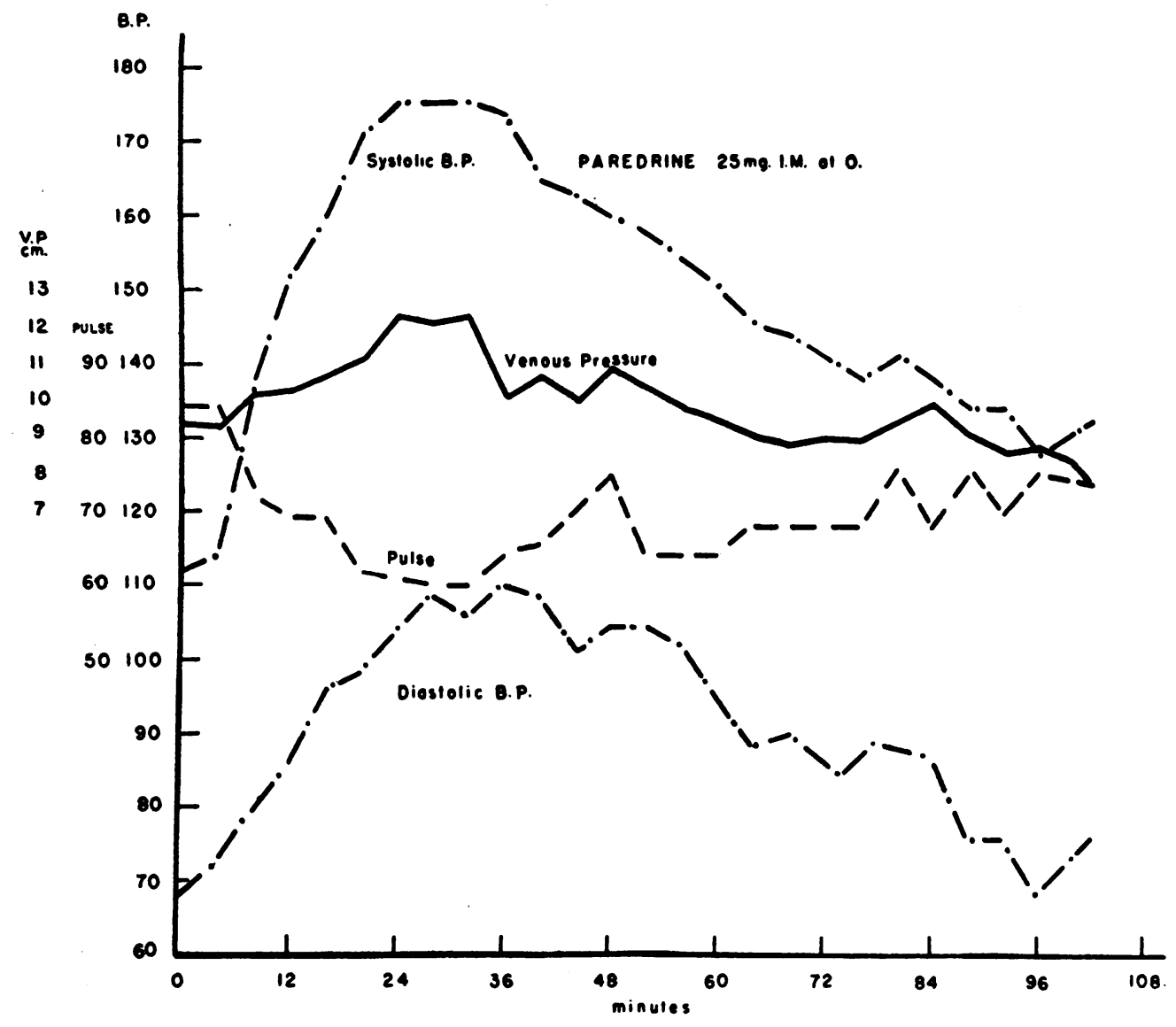

Fig. 2. Increase of Antecubital Venous Pressure after the Administration of Paredrine Intramuscularly

venous pressure reached constant low levels. Venous pressure was measured by the direct method (7) in an antecubital vein at 1-minute intervals; in 2 cases simultaneous measurements were made of pressure in the femoral vein at the level of the inguinal ligament. In the studies on adrenalin the drug was injected into a vein of the arm opposite to that used for venous pressure measurements. Since the changes in cardiovascular dynamics produced by oral administration of paredrine are slow in appearing, and of long duration, venous pressure was determined only initially and at the height of the arterial hypertension in the experiments in which pressor effect of paredrine, three studies were made on normal men to determine the effect of the inhalation of amyl nitrite on the hypertension caused by the administration of paredrine.

Another group of experiments was done on rabbits under nembutal anesthesia. After the injection of paredrine in the ear veins, changes in the veins of the omentum or mesentery of the small intestine of rabbits were determined by measurements of the diameter of the image thrown on a screen by a micro-projector.

In a third group of experiments, three in number, studies were made of the rate of flow of solutions of 
paredrine through a segment of saphenous vein of anesthetized dogs in situ, according to the technique of Donegan (8).

\section{RESULTS}

Oral, intramuscular, or intravenous administration of paredrine in man, in doses which caused a definite elevation of blood pressure, also re- sure reached its highest level, and in all of the experiments the changes in venous pressure were not closely proportional to those of arterial pressure, nor was their time of onset and offset exactly the same. The administration of paredrine produced neither discomfort nor restlessness.

Adrenalin (Figure 10) caused a very rapid and

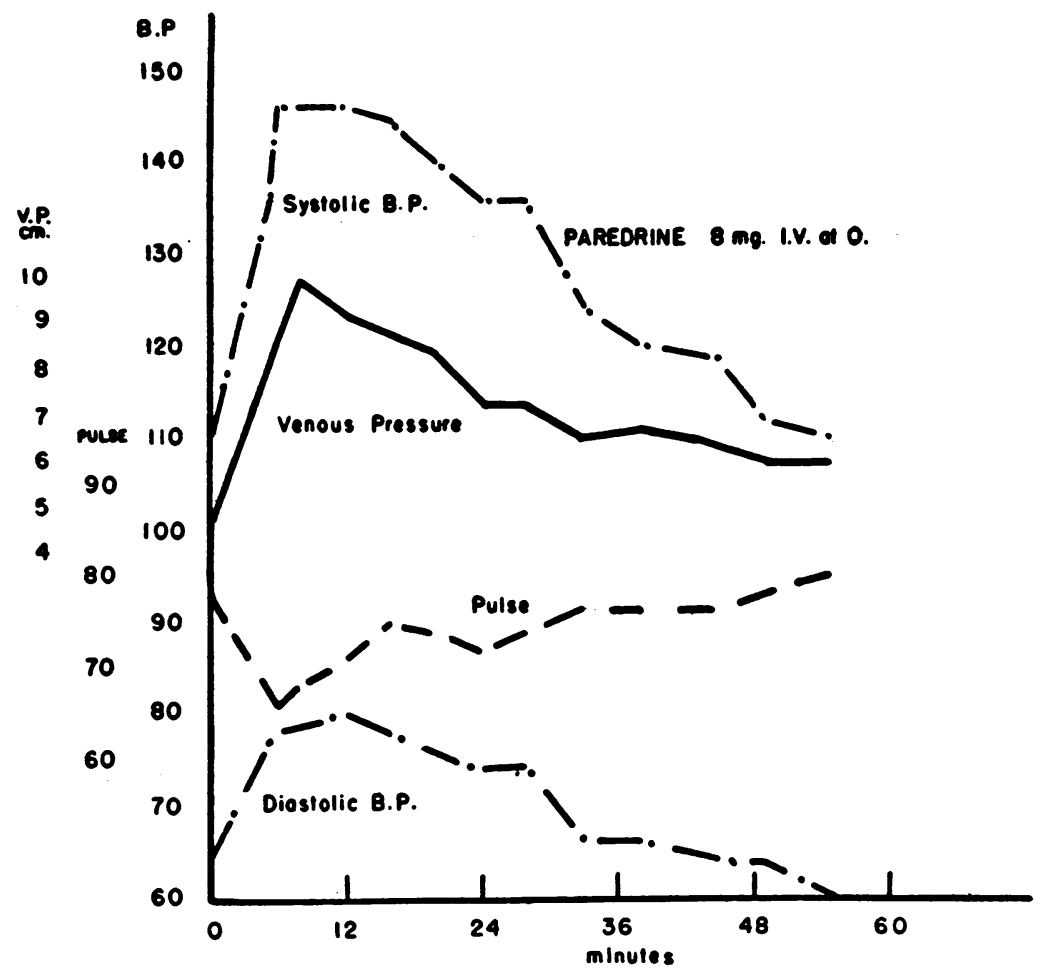

Fig. 3. Increase of Antecubital Venous Pressure after the Administration of Paredrine Intravenously

sulted in a temporary increase in venous pressure of from 2.3 to $6.0 \mathrm{~cm}$. of water (Figures 1 to 7 , 11,12 ). In a few other experiments (not represented in the graphs), no change in venous pressure was found after doses too small to produce increased arterial pressure. The elevation of blood pressure was associated with cardiac slowing, except in the atropinized subjects. In these subjects, a slight increase in heart rate occurred, and increases in both arterial and venous pressure were found to be greater for a given dose of paredrine than in the non-atropinized subjects (Figures 8 and 9). In the two experiments in which the drug was given intramuscularly, the peak of the venous pressure curve was not reached until several minutes after the systolic blood pres- striking increase in venous pressure, with a moderate rise in arterial pressure.

The measurements of the projected diameter of veins of the rabbit showed definite decreases of approximately 20 per cent after the intravenous injection in the ear veins of 5 to $20 \mathrm{mgm}$. of paredrine. In the perfusion experiments on dogs, the rate of flow through the venous segment dropped sharply when dilutions of paredrine of $20 \mathrm{mgm}$. per $100 \mathrm{cc}$. of physiological saline were used. However, no definite effect could be obtained by perfusions with dilutions within the range which the usual dosage could produce in the blood stream of an intact animal receiving the drug parenterally.

Inhalation of amyl nitrite (Figures 11,12) in 

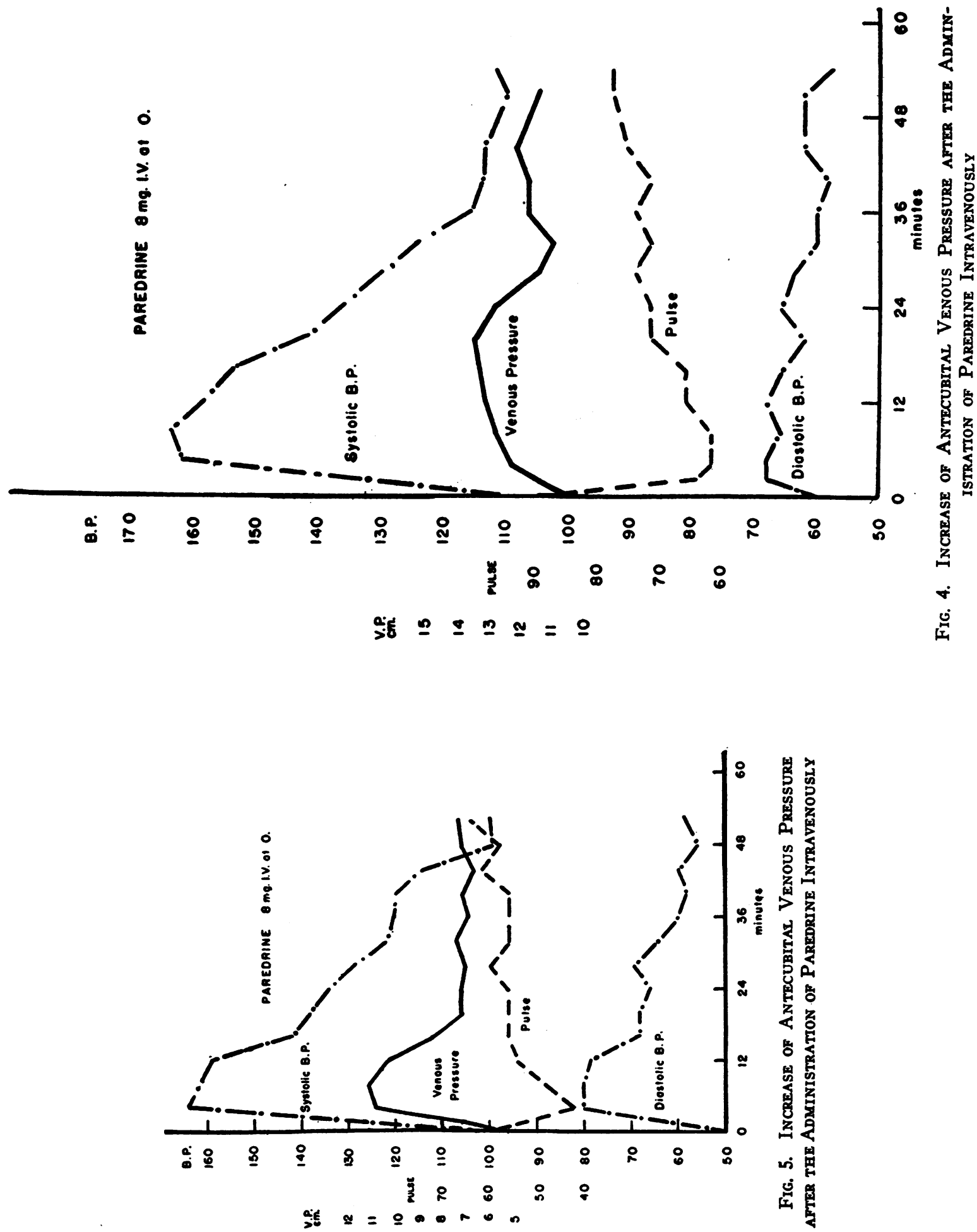

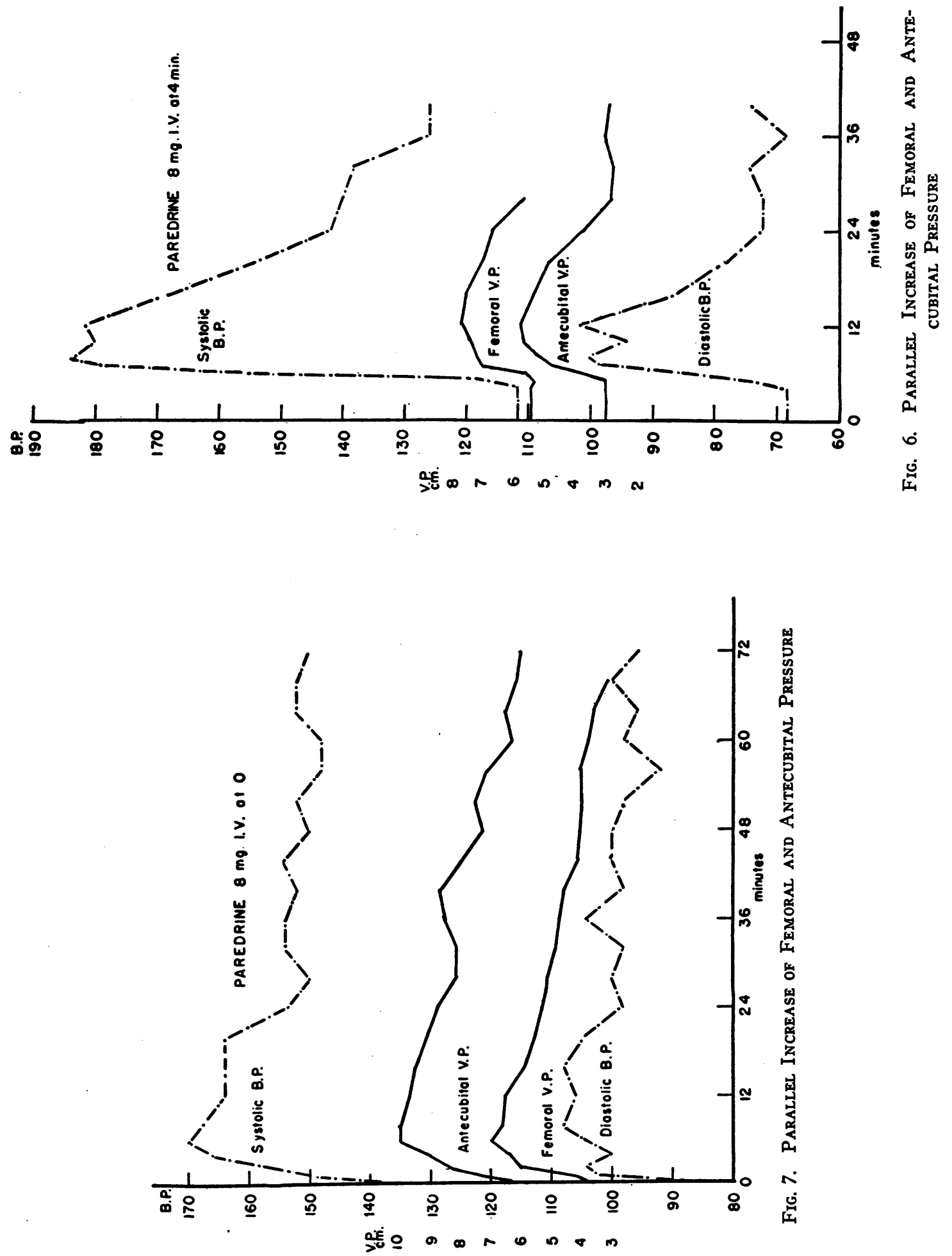


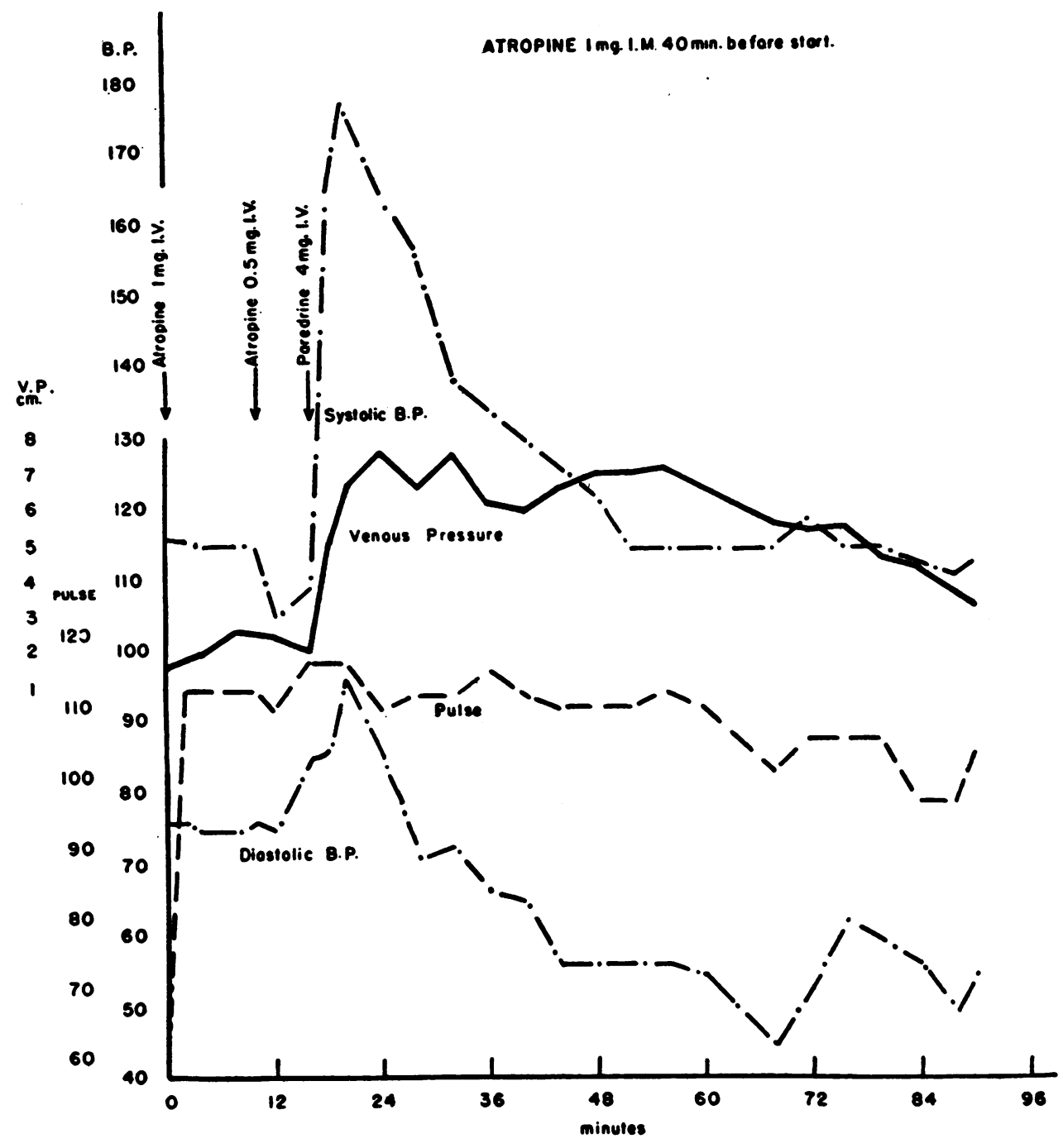

Fig. 8. Effect of the Administration of Paredrine on Atropinized Subjects

the recumbent posture caused a fall of blood pressure to or below normal levels within 30 seconds, and a return to the hypertensive level within 1 minute. The diastolic levels fell relatively more than the systolic. The experiment was repeated three or four times over a 10-minute interval in each subject, with practically identical results. Marked flushing occurred during the inhalation of the drug. Changes in venous pressure were small.

\section{DISCUSSION}

The rise in venous pressure observed after the administrations of paredrine in man is similar to that found by authors who have studied other sympathicomimetic drugs $(2,3,6,9,10,11,12$, 13). The mechanism causing this phenomenon associated with the administration of sympathicomimetic drugs is not definitely established; some workers favor constriction of the veins themselves $(2,3,6,12,13)$, while others regard back-pressure from the heart as the cause $(10,11)$.

Mechanisms which cause rise in venous pressure and deserve consideration here are: $(a)$ increase in intrapleural pressure; (b) changes in tone of the skeletal muscle; (c) transmission of the increased arterial pressure through the capillaries into the veins; $(d)$ back pressure resulting from decreased cardiac output due to the vagal slowing of the heart after the administration of 
paredrine; $(e)$ constriction of the veins; and $(f)$ back pressure due to arterial hypertension.

The first two can be eliminated as causes of the rise in venous pressure due to the administration of paredrine, since the drug causes no change in respiratory dynamics or in the tonus tion of paredrine is additional evidence that transmission of pressure in this manner does not occur.

In the previous study on the action of paredrine in man (1), it was pointed out that slowing of the heart rate presumably due to depressor reflex almost always is associated with the onset of

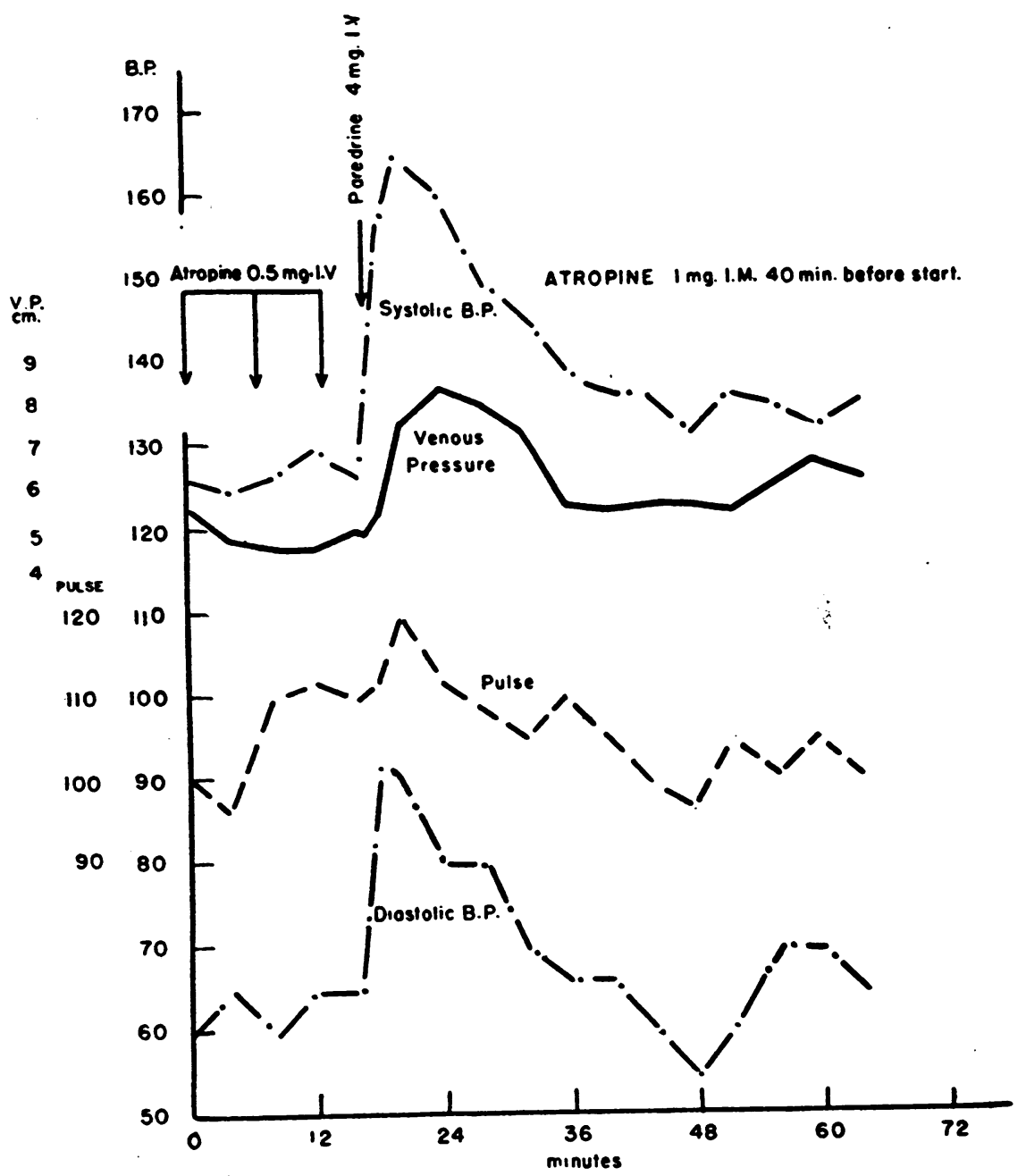

Fig. 9. Effect of the Administration of Paredrine on Atropinized Subjects

of the skeletal musculature. Transmission of increased arterial pressures through the capillaries into the veins is also unlikely, since the elevation in blood pressure caused by paredrine is due to arteriolar spasm (14); Landis (15) has shown that constriction of the arterioles in the frog mesentery due to the administration of adrenalin did not increase the capillary pressure. The absence of venous pulsations after the administra- hypertension due to the action of this drug. In occasional instances a simultaneous slight decrease in cardiac output may also be detected; this might possibly cause an increase in venous pressure. Increase of venous pressure secondary to vagal inhibition of the heart is excluded by the experiments on fully atropinized subjects.

Constriction of the mesenteric veins of the anesthetized rabbit was observed to follow the 


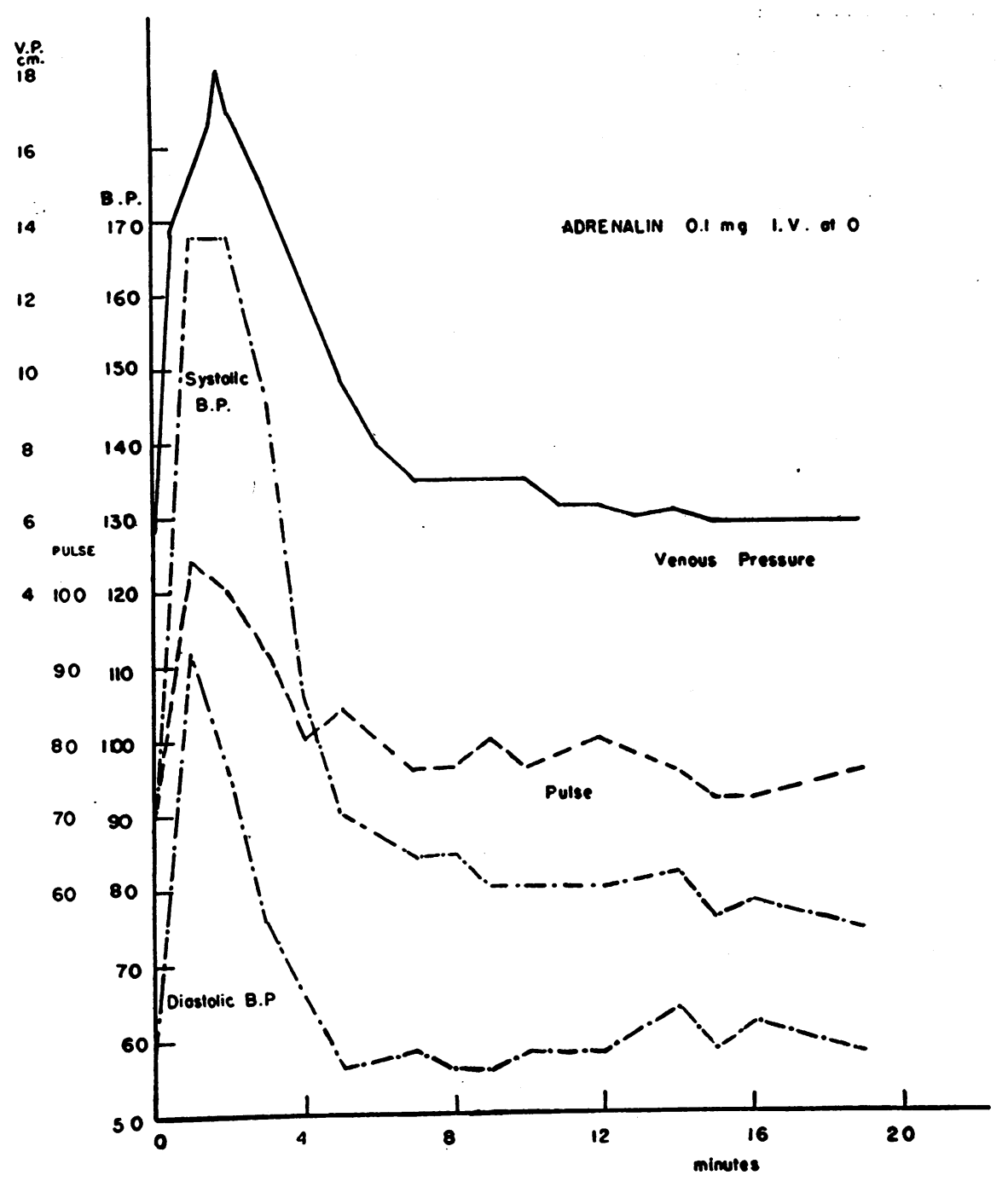

Fig. 10. Effect of Intravenous Administration of Adrenalin

injection of paredrine into an ear vein. Studies on the unanesthetized animal were not possible; the only veins available for direct study in such animals are those in the eye-grounds. These, having no muscle in their walls, are incapable of constriction (16); observation of the retina by means of the ophthalmoscope revealed absence of venous constriction, although the retinal arteries were seen to become markedly narrowed. The findings in the studies on the rate of flow of fluid perfused under a constant head of pressure through isolated veins of anesthetized dogs also suggest that paredrine constricts veins, although the unphysiological nature of the animal preparation makes these findings by themselves incon- clusive. The muscular tone of the vein walls is an important factor in regulation of venous pressure. The resistance of the venous system to central flow of blood is appreciable, as demonstrated by the increase of pressure from the great veins to the capillaries. The discussion of Moritz and von Tabora (7) minimizes the factor of resistance to forward flow of blood in veins, but views the distensibility of venous segments as an important influence on venous pressure. These authors pointed out that if the smooth muscle of the vein wall contracts, a given amount of blood contained within the vein will be under increased tension. Emptying out of the venous "reservoirs" may be considered as a phase of gen- 


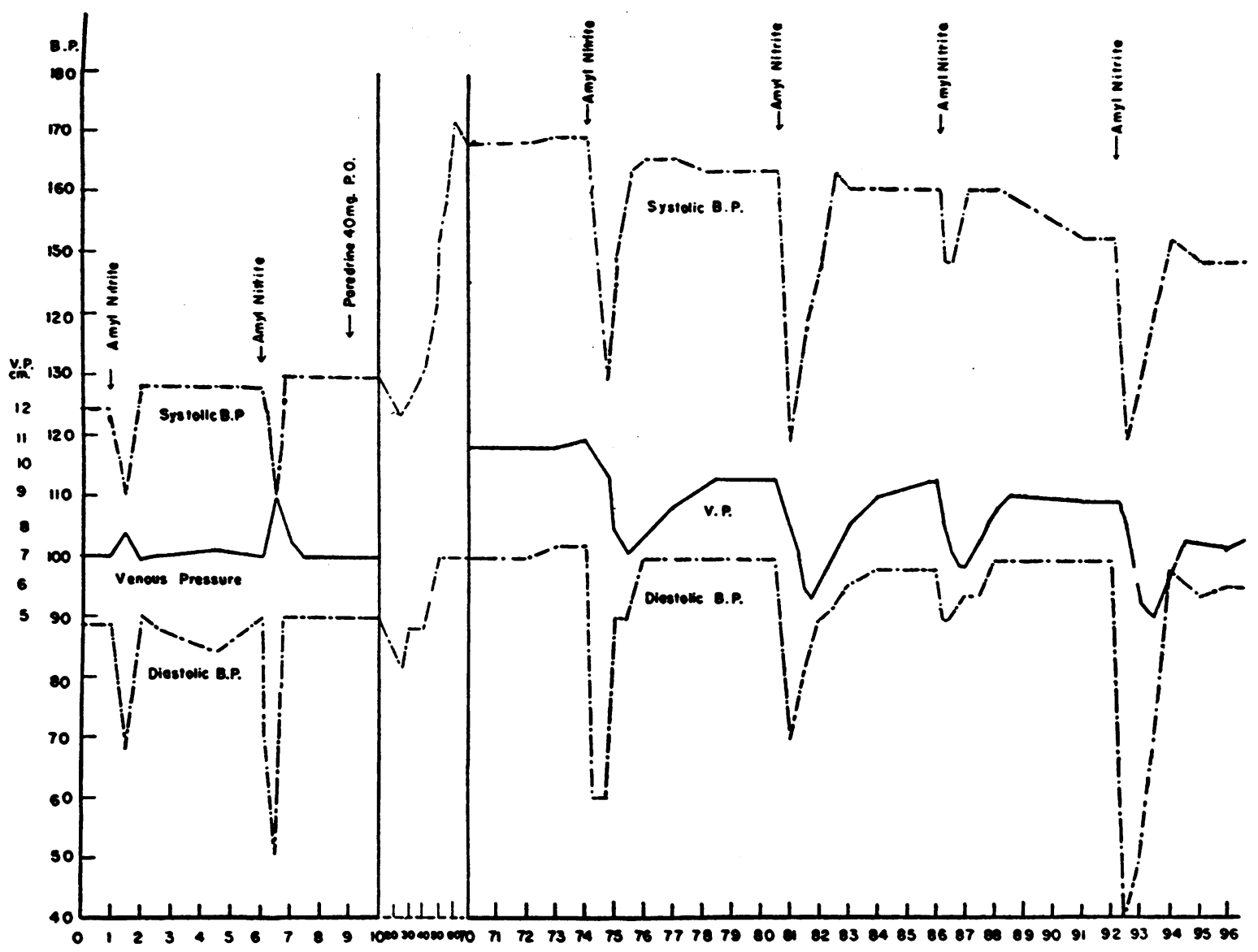

Fig. 11. Effect of Inhalation of Amyl Nitrite after Paredrine Orally

eralized contraction of veins, and might possibly tend to increase venous pressure, at least initially, in a manner similar to an intravenous infusion of a large volume of fluid $(11,17)$. It is most probable that venous constriction is one factor responsible for the rise in venous pressure caused by paredrine. This mechanism is not unique to paredrine, for the venous pressure increase produced by adrenalin in animals and men has been attributed to venous contraction $(9,12,13)$, as has that produced by paredrinol $(2,3,4,6)$.

Measurements of the femoral venous pressure after the administration of paredrine show that the increases in pressure occur in these veins also. These findings indicate that the pressure within the right auricle is also increased, since only large valveless veins lie between the femoral triangle and the heart. The possibility that this increase in venous pressure is due to vagal slowing of the heart is ruled out by the above-de- scribed experiments on atropinized subjects. The mechanism of the increase in right auricular pressure is not clear. Certain pertinent studies have, however, been made by other authors. Early experiments with the heart-lung preparation (18) showed an elevation of venous pressure if the arterial pressure was raised by increasing the peripheral resistance. Starling considered this to be due to back-pressure through the pulmonary circuit. Later workers, however, attributed this finding either to failure of the heart or to increased filling of the auricle due to increased coronary blood flow (19), which in the heartlung preparation is proportionately much larger than in intact animals. The moderate increases of blood pressure which occur in most of the subjects after the administration of paredrine would not produce cardiac failure. Similarly, the absence of decrease of vital capacity rules out back-pressure due to cardiac decompensation. 


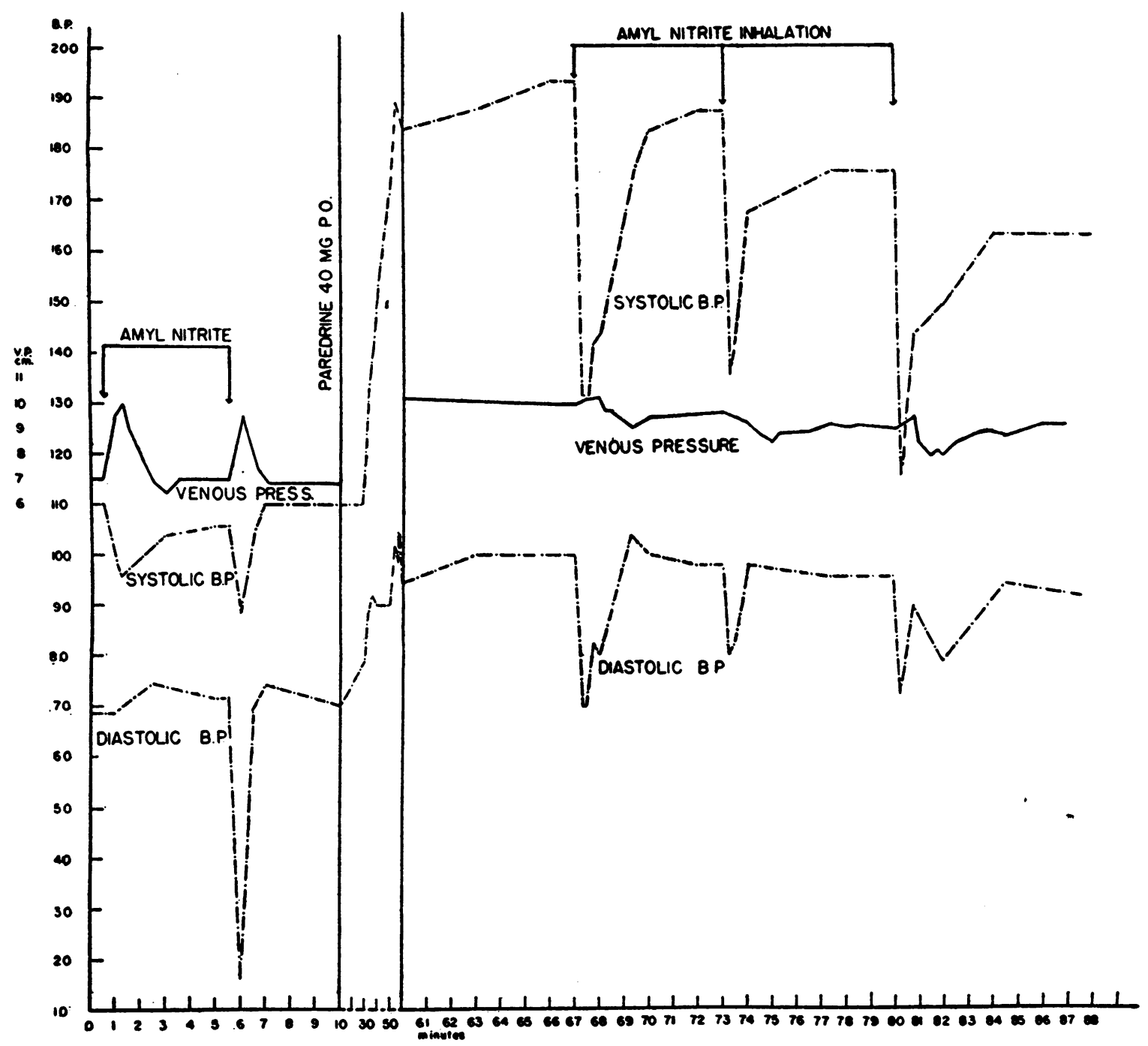

Fig. 12. Effect of Inhalation of Amyl Nitrite after Paredrine Orally

The experiments of De Jäger (20), Katz and Wiggers (21) and Barcroft (22) on intact animals showed that obstruction of the aorta close to the diaphragm usually produced increases of venous pressure. These findings are difficult to relate to the present study since the observations of those authors only lasted a few minutes after the occlusion of the aorta, a time during which major changes in the distribution of the blood might be expected to occur. It is quite possible, however, that paredrine produces increased pressure in the pulmonary arterial tree simultaneously with hypertension in the systemic circulation, and this might be suggested as a cause of increased right auricular and venous pressure. However, in cats, occlusion of as much as 60 per cent of the cross sectional area of the pulmonary artery does not change pressure in the right auricle (23), the venous pressure remaining unchanged until the cardiac output decreases. Since decrease in cardiac output does not occur after the administration of paredrine, it is clear that this mechanism cannot be invoked to explain the rise in auricular pressure caused by the drug. The rise in auricular pressure caused by paredrine must be related to the generalized increase in tonus of the blood vessels throughout the body.

Another important consideration to be discussed is the relation of the increased venous pressure to the arterial hypertension observed after the 
administration of paredrine. Authors who have studied paredrinol $(2,3,4,6)$ have suggested that this drug produces elevation of arterial pressure by increasing the venous return to the heart due to venous constriction. However, many experiments in men and animals show that the intravenous injection of large amounts of fluid $(17,24,25)$ produces only slight changes in arterial pressure; in fact most authors have found that this procedure results in peripheral vasodilatation. The lack of parallelism between venous and arterial pressure curves in our experiments suggests that their variations are produced by independent mechanisms. Since nitrites are said to act chiefly on the veins (26), the observation that nitrites counteract paredrinol hypertension has been used by Stead and Kunkel (6) as evidence that venous changes cause the increased arterial pressure. The rapid decreases in arterial pressure with prompt recovery following inhalation of amyl nitrite are difficult to interpret except as evidence of rapid dilatation and constriction of arterioles; it seems impossible for the veins and "venous reservoirs" to fill and empty so rapidly. It must be concluded that venous constriction is not important in the genesis of the hypertension produced by paredrine in normal man. These findings, however, throw no light on the rôle of venous constriction in recovery from shock.

The pressure increase in the femoral vein indicates that the pressure at the right auricle is probably increased. The classic observations of Starling (27) and Bainbridge (28) would lead one to anticipate increased cardiac output and tachycardia as a result of this increase. Why these changes do not occur is not clear, but the increased pressure load against which the heart works must be an important factor.

\section{CONCLUSIONS}

1. Oral, intramuscular or intravenous injection of paredrine produces a generalized increase of venous pressure in normal man.

2. Evidence is presented that this increase is due to active constriction of the veins produced by local stimulation.

3. Venous constriction is not a factor in the production of arterial hypertension by paredrine.

\section{BIBLIOGRAPHY}

1. Altschule, M. D., and Iglauer, A., The effect of benzedrine ( $\beta$-phenylisopropylamine sulphate) and paredrine ( $\rho$-hydroxy- $\alpha$-methyl-phenylethylamine hydrobromide) on the circulation, metabolism and respiration in normal man. J. Clin. Invest., 1940, 19, 497.

2. Rein, H., Die physiologischen Grundlagen für die Wirkungweise der Versuchssubstanz "Knoll H 75 " (1-p-oxyphenyl-2 methylamin-propan). Klin. Wchnschr., 1937, 16, 700.

3. Grosse-Brockhoff, F., and Kaldenberg, F., Klinische Untersuchungen über die freislaufwirksame substanz H 75 (Veritol). Klin. Wchnschr., 1937, 16, 948.

4. Zipf, K., Die Pharmakologische Wirkung des Veritols. Arch. f. Exper. Path. u. Pharmakol., 1938, 189, 679.

5. Issekutz, Béla von, Jr., Über die Kreislaufwirkung des Oxyphenyl- $\beta$-isopropylamin. Arch. f. Exper. Path. u. Pharmakol., 1939, 192, 414.

6 Stead, E. A., Jr., and Kunkel, P., Mechanism of the arterial hypertension induced by paredrinol ( $\alpha-\mathrm{N}$ dimethyl-p-hydroxyphenylethylamine). J. Clin. Invest., 1939, 18, 439.

7. Moritz, F., and von Tabora, D., Uber eine Methode, beim Menschen den Druck in oberflächlichen Venen exakt zu bestimmen. Deutsches Arch. f. klin. Med., 1910, 98, 475.

8. Donegan, J. F., The physiology of the veins. J. Physiol., 1921, 55, 226.

9. Connet, H., The effect of adrenalin on venous blood pressure. Am. J. Physiol., 1920, 54, 96.

10. Capps, J. A., and Matthews, S. A., Venous blood pressure as influenced by the drugs employed in cardiovascular therapy. J. A. M. A., 1913, 61, 388.

11. Plumier, L., Etude Expérimentale des Variations de la Pression Veineuse. Arch. Inter. d. Physiol., $1909,8,1$.

12. Wilkins, R. W., Weiss, S., and Haynes, F. W., The effect of epinephrin in circulatory collapse induced by sodium nitrite. J. Clin. Invest., 1938, 17, 41 .

13. Budelmann, G., Untersuchungen über den Venendruck, die Vitalkapazität der Lunge und das Herzminutenvolumen bei Gesunden und Herzkranken in Ruhe und bei Kreislaufbelastung. Ztschr. f. Klin. Med., 1935, 127, 15.

14. Iglauer, A., and Altschule, M.D., The pressor action of benzedrine and paredrine. Am. J. M. Sc., 1940, 199, 359.

15. Landis, E. M., Capillary pressure and capillary permeability. Physiol. Rev., 1934, 14, 404.

16. Franklin, K. J., A Monograph on Veins. Charles C. Thomas, Springfield, Ill., 1937.

17. Altschule, M. D., and Gilligan, D. R., The effects on the cardiovascular system of fluids administered intravenously in man. II. The dynamics of the circulation. J. Clin. Invest., 1938, 17, 401.

18. Fühner, H., and Starling, E. H., Experiments on the pulmonary circulation. J. Physiol., 1913, 47, 286. 
19. Anrep, G. V., and Bulatao, E., Observations on the pulmonary circulation. Pulmonary circulation in the heart-lung preparation. J. Physiol., 1925, 60, 175.

20. De Jäger, S., Experiments and considerations on hemodynamics. J. Physiol., 1886, 7, 130.

21. Katz, L. N., and Wiggers, C. J., The influence of high systemic blood pressures on the right ventricle and pulmonary circuit. Am. J. Physiol., 1927, 82, 91.

22. Barcroft, H., Cardiac output and blood distribution. J. Physiol., 1931, 71, 280.

23. Gibbon, J. H., Jr., Hopkinson, M., and Churchill, E. D., Changes in the circulation produced by gradual occlusion of the pulmonary artery. J. Clin. Invest., 1932, 11, 543.
24. Lesser, L. von, Surgical Emergencies. Bermingham and Co., New York, 1883.

25. Meek, W. J., and Eyster, J. A. E., The effect of plethora and variations of venous pressure on diastolic size and output of the heart. Am. J. Physiol., 1922, 61, 186.

26. Wilkins, R. W., Haynes, F. W., and Weiss, S., The rôle of the venous system in circulatory collapse induced by sodium nitrite. J. Clin. Invest., 1937, 16, 185.

27. Knowlton, F. P., and Starling, E. H., The influence of variations in temperature and blood pressure on the performance of the isolated mammalian heart. J. Physiol., 1912, 44, 206.

28. Bainbridge, F. A., The influence of venous filling upon the rate of the heart. J. Physiol., 1915, 50, 65. 